\title{
O fanzine digital como estratégia didática na formação inicial do pedagogo para o Ensino de Ciências
}

\author{
The digital fanzine as a didactic strategy in the initial training of the \\ pedagogue for science teaching
}

\section{El fanzine digital como estrategia didáctica en la formación inicial del pedagogo para la enseñanza de las ciencias}

\author{
Raquel Crosara Maia Leite (raquelcrosara@ufc.br) \\ Universidade Federal do Ceará-UFC. \\ Raquel Sales Miranda (raquelsales@ufc.br) \\ Universidade Federal do Ceará-UFC.
}

Jarbas de Negreiros Pereira (jarbasnegreiros03@gmail.com)

Universidade Federal do Ceará-UFC.

Maria Costa de Mendonça (mariacostademendonca@gmail.com)

Universidade Federal do Ceará-UFC.

Resumo: O fanzine é uma revista artesanal, independente e de baixo custo, o que torna possível sua utilização como um recurso didático. Dessa forma, objetivou-se relatar a atividade de elaboração de fanzines digitais por estudantes de Pedagogia como recurso didático no Ensino de Ciências, bem como refletir acerca da relevância da atividade mencionada para a formação inicial do pedagogo no que tange ao conhecimento de estratégias diversas para o Ensino de Ciências. Para tanto, os discentes, em equipe, elaboraram fanzines com a temática: "A cozinha como espaço para ensinar Ciências". Os fanzines foram confeccionados com subtemas diversos, envolvendo segurança alimentar, doenças relacionadas aos alimentos, atividades culinárias, transformações químicas, entre outros. Notou-se que alguns estudantes optaram por temas que já faziam parte do seu cotidiano ou que já haviam tido contato. Enquanto outros abordaram aspectos sociais, econômicos e ambientais em seus fanzines. Dessa forma, este trabalho evidenciou que a elaboração de fanzines que abordam temas científicos permitem a aproximação de conhecimentos do cotidiano dos estudantes aos conhecimentos científicos como também, percebeu-se que os fanzines agregam aprendizagens e posturas que beneficiam a formação inicial do pedagogo e sua atuação no ensino de Ciências.

Palavras-chave: Fanzines; formação de professores; ensino de ciências.

Abstract: Fanzine is a handmade, independent and low-cost magazine, which makes it possible to use it as a teaching resource. Thus, there was a goal to report the activity of the development of digital fanzines by students of Pedagogy as a didactic resource in Science Education, as well as to reflect on the relevance of the mentioned activity for the initial education of the pedagogue regarding the knowledge of different strategies for science teaching. To this end, the students, as a team, developed fanzines with the theme: "The Recebido em: 23/04/2021

Aceite em: 20/09/2021 
kitchen as a space to teach Science". The fanzines were made with different sub-themes, involving food security, food-related diseases, culinary activities, chemical transformations, among others. It was noted that some students chose themes that were already part of their daily lives or that they already had contact with. While others addressed social, economic and environmental aspects in their fanzines. Thus, this work evidenced that the development of fanzines that address scientific themes allows the approximation of students' daily knowledge to scientific knowledge, also, it was noticed that fanzines add learning and postures that benefit the initial education of the pedagogue and his performance in science teaching.

Keywords: Fanzines; teacher training; science teaching.

Resumen: El fanzine es una revista artesanal, independiente y de baja inversión financiera, que permite utilizarla como recurso didáctico. Así, el objetivo fue reportar la actividad de desarrollo de fanzines digitales por parte de estudiantes de Pedagogía como recurso didáctico en Educación Científica, así como reflexionar sobre la relevancia de dicha actividad para la formación inicial del pedagogo en lo que se refiere al conocimiento de diferentes estrategias para la enseñanza de las ciencias. Para ello, los alumnos, en equipo, desarrollaron fanzines con el tema: "La cocina como espacio para la enseñanza de la ciencia". Los fanzines se realizaron con diferentes subtemas, que involucran seguridad alimentaria, enfermedades relacionadas con la alimentación, actividades culinarias, transformaciones químicas, entre otros. Se notó que algunos estudiantes eligieron temas que ya formaban parte de su vida diaria o con los que ya habían tenido contacto. Mientras que otros abordaron aspectos sociales, económicos y ambientales en sus fanzines. Así, este trabajo mostró que el desarrollo de fanzines que abordan temas científicos permite la aproximación del conocimiento diario de los estudiantes al conocimiento científico, así como, se notó que los fanzines agregan aprendizajes y posturas que benefician la formación inicial del pedagogo y su desempeño en la enseñanza de las ciencias.

Palabras-clave: Fanzines; formación de profesores; enseñanza de la ciencia.

\section{INTRODUÇÃO}

A disciplina de Ensino de Ciências presente no currículo do curso de Pedagogia da Universidade Federal do Ceará (UFC) se configura como um relevante aporte teórico e prático para a formação inicial do pedagogo no que tange às Ciências e suas tecnologias. Vale ressaltar que a disciplina supracitada, cuja carga horária é de 96 horas ou 6 créditos, é o único componente obrigatório ao longo da licenciatura em Pedagogia que trata de temas específicos de Ciências.

O tempo destinado ao Ensino de Ciências ao longo da licenciatura é escasso (MIOLA; PIEROZAN, 2015, BERALDO; CEZARI, 2012). Dessa forma, as experiências proporcionadas durante a disciplina de Ensino de Ciências contribuem para uma visão mais ampliada do pedagogo em formação acerca do que é Ciência, o que ensinar em Ciências,

Recebido em: 23/04/2021

Aceite em: 20/09/2021 
como ensinar Ciências e porque ensinar Ciências. Refletir e questionar as concepções sobre o que é o conhecimento científico, sua origem e produção, contribui para a formação dos professores. Em relação à licenciatura em Ciências Biológicas, Oestreich et al. (2021, p. 162) afirmam que "estar atento e discutir acerca destas concepções já na formação inicial docente é fundamental". Para os futuros pedagogos, que irão abordar temas de Ciências da Natureza, ampliar o entendimento sobre natureza da ciência e sobre o seu ensino é questão primordial.

A utilização de linguagens e estratégias diversas como instrumento de Ensino de Ciências se torna imprescindível à trajetória do pedagogo em formação. Nesse sentido, os fanzines se configuram como uma estratégia didática que pode proporcionar aos estudantes acesso aos temas científicos por meio do uso de diferentes linguagens (escrita, desenhos, colagens etc.). Como indicam Coutinho e Miranda (2019, p. 222) é "necessário que nos cursos de licenciatura sejam desenvolvidas formas diferenciadas e inovadoras para abordar os conteúdos em sala de aula[...]".

Além disso, alguns autores afirmam que a educação científica deve passar por algumas reorientações para que os estudantes possam aprender Ciências (POZO; CRESPO, 2009, CACHAPUZ et al., 2011).

Assim, o presente trabalho visa relatar a atividade de elaboração de fanzines digitais por estudantes de Pedagogia como recurso didático no Ensino de Ciências, bem como refletir acerca da relevância da atividade mencionada para a formação inicial do pedagogo no que tange ao conhecimento de estratégias diversas para o Ensino de Ciências.

\section{PERCURSO METODOLÓGICO}

A atividade foi desenvolvida com discentes do curso de pedagogia da Universidade Federal do Ceará, mais especificamente na disciplina de Ensino de Ciências (semestre 2020.1). A escolha dos sujeitos se justifica devido a um dos autores ser docente da referida instituição. Além disso, vale ressaltar que há uma urgente necessidade de formação científica dos profissionais docentes que logo mais estarão (ou já estão) no ambiente escolar, considerando o forte embate que a ciência tem enfrentado.

Para tanto, havendo a devida orientação da turma com todo o aporte teórico referente aos fanzines, a turma foi dividida em sete equipes para a elaboração de um exemplar com a seguinte temática: A cozinha como espaço para ensinar Ciências. Tal temática foi propícia Recebido em: 23/04/2021

Aceite em: 20/09/2021 
neste momento, pois como estamos num período de pandemia (Covid-19) as pessoas estão mais caseiras, com um tempo maior de fazerem suas atividades domésticas, e nada melhor do que aproveitar o espaço da casa que mais se parece com um laboratório, onde acontece corriqueiras reações e transformações da matéria que é a cozinha.

Dada a referida temática os discentes iniciaram a produção de seus fanzines, seguindo as básicas etapas da fanzinagem, a saber: planejamento, confecção, reprodução e distribuição. Portanto os discentes realizaram seus planejamentos mesclando em discussões e pesquisas para a realização, tudo via online por aplicativos diversos. Na confecção dos fanzines é importante considerar a composição por textos e/ou imagens, podendo ocorrer variações nos seus formatos e na paginação. Já na reprodução podem ocorrer tiragens de dezenas a centenas de exemplares, no caso foram feitos apenas um exemplar por equipe.

No final da disciplina todas as equipes socializaram suas produções apresentadas por meio da plataforma do Google Meet, devido a adoção do colegiado da universidade pelo modelo de ensino online por conta da pandemia. Já com relação a distribuição de seus fanzines, eles poderiam ser vendidos, trocados ou simplesmente distribuídos entre amigos, familiares, vizinhos e outros. No caso dos discentes, ficou a critério livre, como também, todas as etapas perpassaram pela liberdade, imaginação e criatividade na confecção dos fanzines, já que, conforme MAGALHÃES (2013, p.45), "não existem regras para a produção do fanzine".

\section{DO CONHECIMENTO COTIDIANO AO CIENTÍFICO: O FANZINE COMO ESTRATÉGIA DE ARTICULAÇÃO}

Os fanzines, zines, ou ainda, e-zines (versão digital de um fanzine) são revistas produzidas de forma artesanal, sem formato padrão, cuja produção é independente e de baixo custo. Esse tipo de publicação surgiu na década de 1930 e geralmente retrata alguma temática de interesse de seus autores, pois como afirma Magalhães (2013), os fanzines são produzidos por fãs (ou aficionados) para outros fãs que tenham o mesmo interesse.

De acordo com Lima e Miranda (2010, p. 52): “Como produções que não possuem estrutura definida previamente, [...] os zines geralmente passam incólumes à produção em série, massificada, típica às produções grã-midiáticas."

Recebido em: 23/04/2021

Aceite em: 20/09/2021 
Os fanzines são considerados instrumentos de expressão dos sujeitos, pois eles oportunizam aos seus autores a possibilidade de participar de todas as etapas de construção da revista e de exercer sua autoria criativa (MUNIZ, 2010, SANTOS NETO, 2010).

Dessa forma, os zineiros (produtores de fanzines) podem utilizar diferentes texturas, colagens, sobreposições e organizações textuais para compor suas revistas. Essa liberdade de construção possibilita o exercício da autoria livre de padrões estéticos e comerciais a que são submetidas as revistas de grande circulação (LEITE; MIRANDA; MOTA, 2020).

De acordo com Nascimento (2010, p. 125), a prática de produzir fanzines possibilita: "[...] formas de aprender, construindo e reconstruindo saberes que potencializem o poder de intervir como sujeitos pensantes no meio sociocultural."

Assim, os fanzines se apresentam como um recurso didático que possibilita a articulação entre os conhecimentos cotidianos e científicos e o contexto no qual os estudantes estão inseridos (BEZERRA; SANTOS, 2016). Conforme previsto na Base Nacional Comum Curricular (BNCC): "É necessário destacar que, em especial nos dois primeiros anos da escolaridade básica, [...], as habilidades de Ciências buscam propiciar um contexto adequado para a ampliação dos contextos de letramento (BRASIL, 2017, p. 331)”.

Lorenzetti e Delizoicov (2001) destacam a importância do desenvolvimento da alfabetização científica já no início do processo de escolarização das crianças ainda que estas não sejam capazes de codificar/decodificar o sistema alfabético de escrita nesse estágio. Os saberes cotidianos que os estudantes trazem consigo podem propiciar contextos e pontos de partida para o trabalho com temas científicos, já que antes mesmo de adentrar à escola, as crianças já detêm conhecimentos prévios advindos das vivências com o mundo e pessoas que as cercam.

Dessa forma, a contextualização dos temas científicos considerando a realidade dos estudantes aproximam os conhecimentos prévios dos científicos sistematizados pela escola no que tange à introdução de conceitos científicos mais complexos. Bezerra e Santos (2016), em uma sequência didática, estimularam seus alunos da Educação de Jovens e Adultos (EJA) a produzirem fanzines, a partir da articulação dos seus saberes cotidianos com a investigação sobre o tema (impactos ambientais). Para as autoras foi possível reconhecer que os estudantes ressignificaram seus saberes, a partir da reflexão sobre o seu cotidiano e os conteúdos científicos estudados para a produção do fanzine.

Recebido em: 23/04/2021

Aceite em: 20/09/2021 
Bizzo (2009) afirma que o conhecimento cotidiano se baseia em diferentes fontes de informação tais como as de cunho religioso, cultural e até mesmo científico. O conhecimento científico, diante de contradições, utiliza-se do confronto de ideias a fim de gerar um denominador comum entre estas; utiliza-se, também, de uma terminologia compartilhada por todos aqueles que dela fazem uso, independente da região geográfica na qual estão inseridos.

Nesse contexto, é importante que os pedagogos em formação reflitam sobre como tornar a linguagem científica acessível e compreensível para seus estudantes, buscando que eles entendam e utilizem a terminologia científica de maneira correta. E incentivá-los a produzir textos é uma alternativa para atingir esse objetivo. Portanto, percebe-se que os fanzines representam excelente ferramenta para a educação, pois eles permitem a expressão artística e crítica dos estudantes. No entanto, segundo Magalhães (2013), a grande maioria dos professores ainda não conhece essa ferramenta didática, por isso é importante divulgar os trabalhos pedagógicos que utilizam os fanzines. Da mesma forma, são poucas as pesquisas que abordam a contribuição do fanzine para o Ensino de Ciências.

\section{A ELABORAÇÃO DE FANZINES DIGITAIS COMO ATIVIDADE NA FORMAÇÃO INICIAL DO PEDAGOGO PARA O ENSINO DE CIÊNCIAS}

A elaboração de fanzines é uma atividade democrática e plural. Além disso, "uma outra vantagem é que o fanzine [...] revela-se também como um instrumento enriquecedor das "vozes" dos estudantes, comunicando significados, construindo e reconstruindo saberes" (NASCIMENTO, 2010, p.126). Por esses e outros motivos, o trabalho com fanzines em diversas disciplinas e níveis de ensino tem feito parte do repertório dos professores. A disciplina de Ensino de Ciências para estudantes de Pedagogia realizada no semestre 2020.1, teve como uma de suas propostas o trabalho com a produção de fanzines de temas científicos.

Devido ao contexto de pandemia e isolamento social enfrentados pela sociedade atualmente, a referida disciplina, assim como as demais, ocorreu de modo remoto ${ }^{1}$. Dessa forma, a produção de fanzines manuais apresentou-se como um desafio, uma vez que os estudantes não disporiam das mesmas possibilidades oferecidas pelo ensino presencial. Assim, os fanzines digitais ou e-zines foram o instrumento de divulgação científica produzido pelos estudantes de Pedagogia na disciplina de Ensino de Ciências.

${ }^{1}$ As aulas foram transmitidas semanalmente pelo Google Meet.

Recebido em: 23/04/2021

Aceite em: 20/09/2021 
A proposta de atividade de produção de fanzines com temáticas científicas teve como "tema norteador" a cozinha como espaço para ensinar Ciências, haja vista as possibilidades que este tema oportuniza para o trabalho com aspectos históricos, culturais, sociais, econômicos etc. Vale ressaltar que apesar de ter sido definida um tema central, cada grupo teve a possibilidade de escolher o subtema ou questão que iria abordar em sua produção, pois como afirma Magalhães (2013, p. 67): "É importante frisar que o trabalho pedagógico com fanzines deve preservar a liberdade de escolha dos alunos, princípio que rege o conceito desse tipo de publicação."

Além do aporte teórico e discussões sobre os conhecimentos cotidiano e científico, superstições, mitos, costumes e ciência na cozinha, os estudantes receberam orientações quanto à elaboração dos fanzines: atividade em grupo ou individual, tempo no cronograma da disciplina destinado à produção dos fanzines, articulação entre as equipes, pesquisa sobre a temática escolhida, dentre outras. Uma vez definidas as equipes e os assuntos a serem abordados, os estudantes iniciaram a pesquisa e desenvolvimento dos fanzines. Durante os encontros síncronos e comunicação no grupo de mensagens instantâneas da disciplina que antecederam a produção dos fanzines.

A opção pela construção dos fanzines, preferencialmente em equipe, coaduna com o pensamento de Nascimento (2010), que afirma que: “[...] o trabalho com o zine, de forma coletiva, proporciona aos estudantes a socialização de ideias, discutindo preferências estéticas de cada um quanto às formas de organizar imagens e textos" (NASCIMENTO, 2010, p.129). Além disso, a criação dos fanzines busca superar uma posição individualista e passiva na aprendizagem dos conteúdos. Busca assim, estimular a participação ativa e criativa dos estudantes e dessa forma, socializar o conhecimento valorizando a autonomia pela utilização de diversas linguagens artísticas (BEZERRA et al, 2017).

Notou-se que alguns estudantes optaram por temas que já faziam parte do seu cotidiano ou que já haviam tido contato. Essa escolha é interessante porque possibilita enfrentar um dos problemas da aprendizagem de Ciências apontados por Pozo e Crespo (2009): a não aplicação do conhecimento científico à vida cotidiana. Assim, a partir da elaboração dos fanzines os estudantes podem estabelecer relações entre o conhecimento científico e o cotidiano. Dessa forma, no Quadro 1, podem ser vistos os temas apresentados nos fanzines produzidos:

Quadro 1- Temáticas dos fanzines produzidos pelos estudantes

Recebido em: 23/04/2021

Aceite em: 20/09/2021 
Fanzine
1. Mitos e verdades na cozinha
Desmistificou alguns dos conhecimentos do senso comum presentes na cozinha;
2. Doenças transmitidas por alimentos
Como o título sugere, elencou informações importantes acerca dos principais agentes e alimentos causadores desse tipo de doenças, e como se prevenir destas;

Abordou questões relacionadas à segurança alimentar, tais como a importância de sempre atentar para o prazo de validade dos alimentos e seguir as instruções contidas nos rótulos;
4. Cozinha segura

5. Dinossauros na cozinha

6. Atividades culinárias em família e seus benefícios para o desenvolvimento da criança

7. Transformações químicas dos alimentos
Abordou o manuseio e a utilização correta de aparelhos e utensílios presentes na cozinha (micro-ondas, facas, panelas de pressão etc.), como identificar um vazamento de gás de cozinha e como apagar um incêndio causado por óleo etc.;

Apresentou um breve panorama acerca da descoberta de fósseis desses animais préhistóricos e a ligação entre estes e o petróleo/gás natural que utilizamos em nossas casas;

Apresentou a cozinha como espaço de interação e propício à construção de conhecimentos através da execução de receitas simples com a participação das crianças;

Apresentou de forma sucinta o que são tais transformações e como ocorrem utilizando exemplos presentes na cozinha, tal como a reação química que ocorre na preparação do café.

Fonte: Os autores.

Um dos fanzines: "O uso de chás substituindo medicamentos manipulados" (FIGURA 1), apresenta os benefícios dos chás naturais para a saúde e os dados que já foram comprovados cientificamente sobre os efeitos destes no corpo humano. Dessa forma, os estudantes construíram o fanzine a partir de um conhecimento cotidiano e se aproximaram da mudança conceitual, apontada por Pozo e Crespo (2009) como necessária para alcançar o conhecimento científico.

Um outro exemplo de fanzine com um tema pertencente à realidade dos estudantes que o produziram foi o intitulado "Intolerância à lactose". No fanzine supracitado, as autoras além 
de apresentarem o que é, quais as causas e sintomas da intolerância à lactose, ainda divulgaram algumas sugestões de receitas que não contêm lactose.
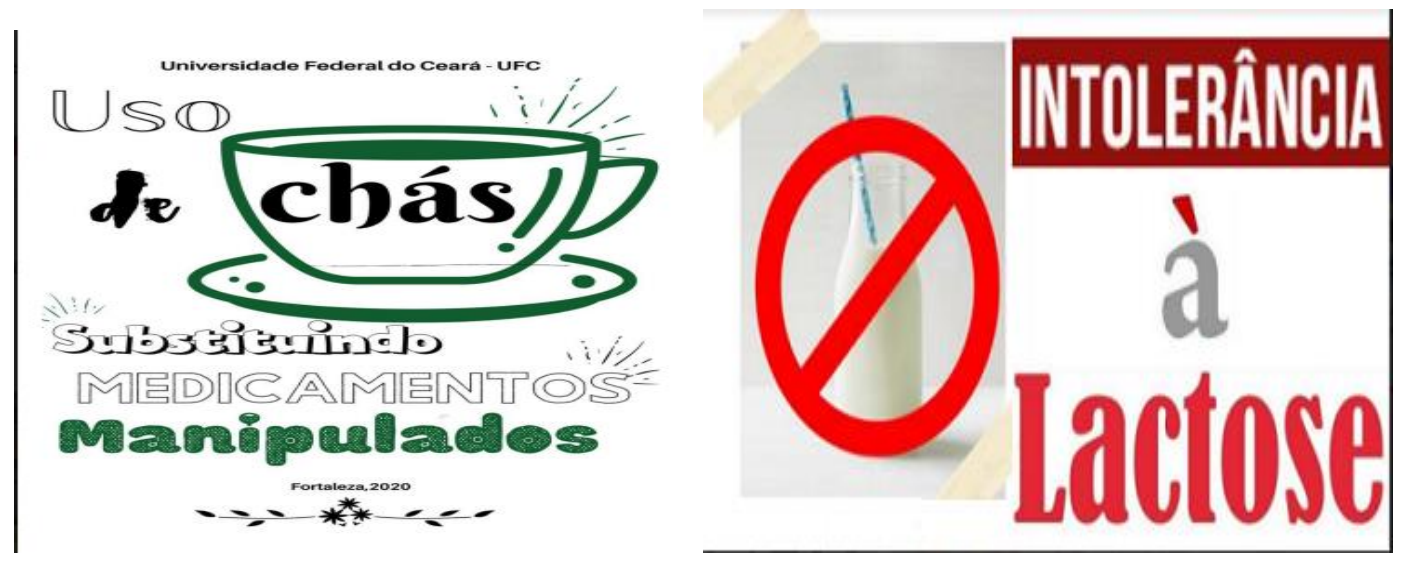

Figura 1- Capas dos fanzines sobre o uso de chás medicinais e sobre intolerância à lactose, respectivamente

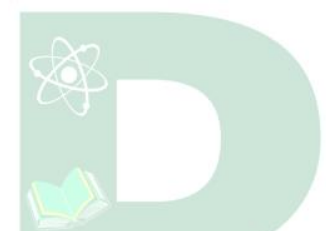

Fonte: Os autores.

Os aspectos sociais, econômicos e ambientais também foram temas abordados no fanzine intitulado "Desperdício na cozinha" (FIGURA 2). Tal fanzine apresentou reflexões importantes quanto à problemática do desperdício de alimentos no Brasil e no mundo, as causas do referido desperdício e as consequências disto para a população e o meio ambiente.
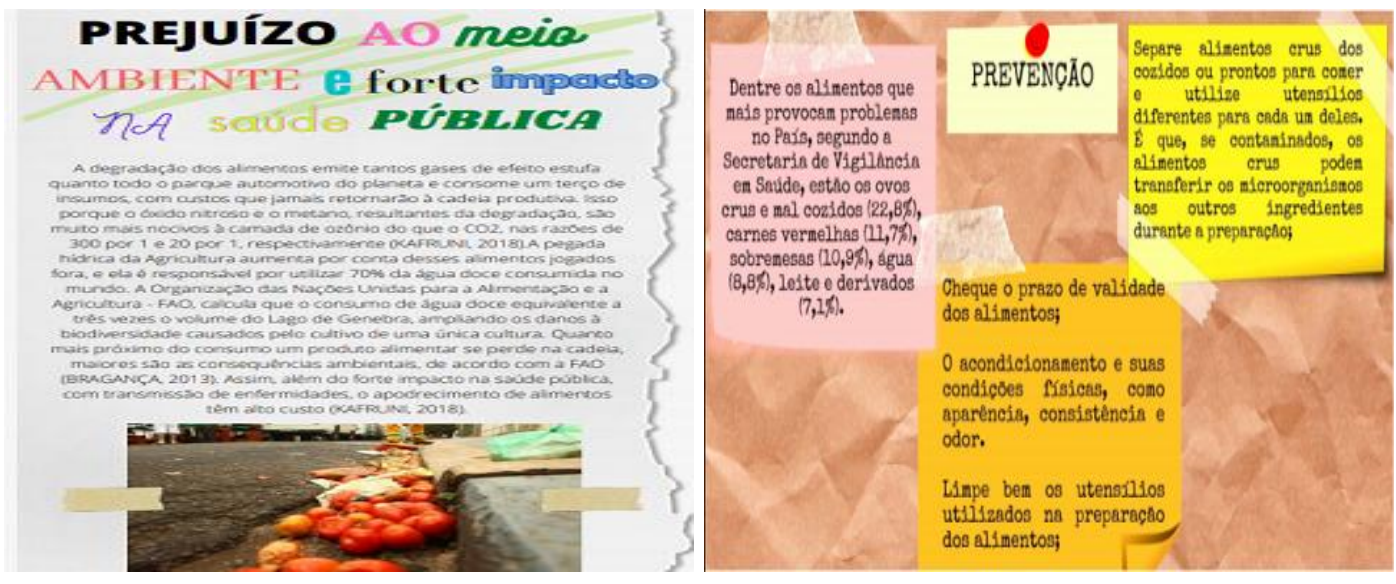

Recebido em: 23/04/2021

Aceite em: 20/09/2021 
Figura 2- Páginas dos fanzines sobre o desperdício e doenças transmitidas por alimentos,

respectivamente

Fonte: Os autores.

Percebe-se que apesar dos fanzines terem sido sobre o tema central cozinha, as temáticas definidas foram bastante amplas, envolvendo segurança alimentar, doenças relacionadas aos alimentos (FIGURA 2), atividades culinárias (FIGURA 3), transformações químicas e um dos grupos estabeleceu uma relação entre os dinossauros e a cozinha (FIGURA 3). Assim, cada equipe focou numa subtemática de seu interesse, o que segundo Cachapuz et al. (2009) é importante para a reconstrução de conhecimentos e a aprendizagem de Ciências.
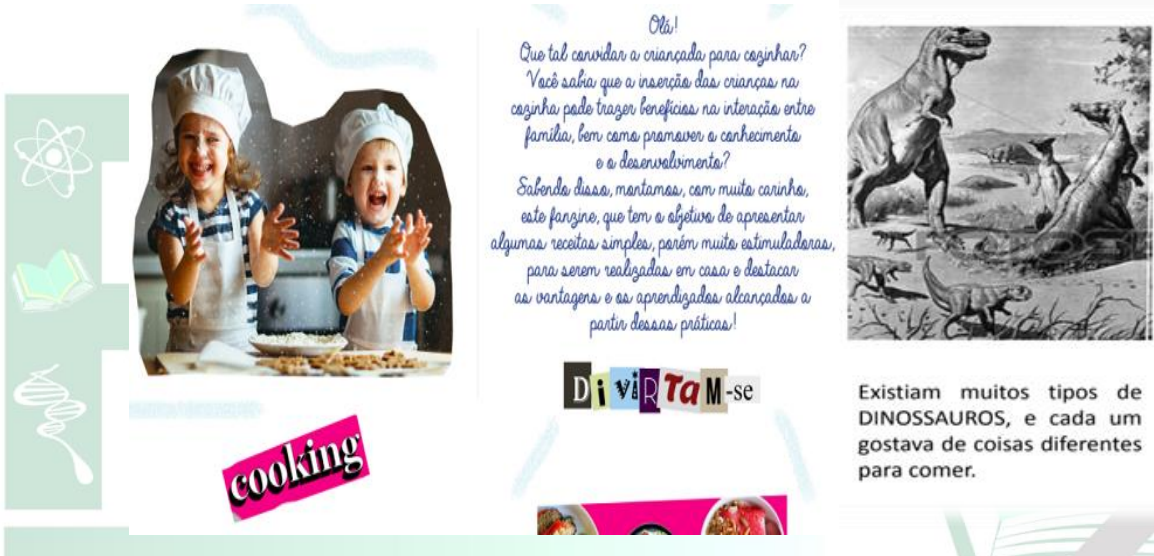

Há MILHÕES de anos atrás o planeta terra era povoado por animais chamados DINOSSAUROS

Figura 3- Páginas dos fanzines sobre atividades culinárias e dinossauros na cozinha, respectivamente

Fonte: Os autores.

A atividade de pesquisa indispensável à elaboração dos fanzines possibilitou aos estudantes conhecerem mais profundamente sobre os assuntos escolhidos para serem abordados e isso pode impactar a futura atuação dos professores em formação, já que de acordo com Leite, Miranda e Mota (2020, p. 173), “[...] quando o professor passa por esse processo de produção fanzínica, se apropria melhor do processo e pode ser capaz de entender como ele pode contribuir para a formação de seu aluno".

Além disso, o processo de elaboração dos fanzines se fez importante por permitir que os estudantes realizassem suas pesquisas sobre os temas científicos, de modo a evitar uma aprendizagem focada no professor e baseada no que Pozo e Crespo (2009) apontam como 'conhecimentos pré-cozidos'. 
Andraus (2013) e Nascimento (2010) orientam sobre a importância de adotar os fanzines em escolas e universidades, pois: “[...] os educadores precisam vislumbrar a importância desempenhada pelo fanzine na constituição de valores éticos e estéticos no exercício da cidadania e constituição dos educandos (NASCIMENTO, 2010, p.132)”.

Outro ponto importante na elaboração dos fanzines foi a possibilidade de os estudantes trabalharem conteúdos significativos para eles, pois segundo Pozo e Crespo (2009), os estudantes aprendem mais quando são capazes de dotar de significado uma informação. Dessa forma, o uso de fanzines no Ensino de Ciências pode contribuir para evitar o que Pozo e Crespo (2009) definem como a utilização de conhecimentos pré-cozidos ou prontos para o consumo, pois durante a construção dos fanzines, a aprendizagem foi sendo construída a partir das pesquisas e edições realizadas pelos autores.

Dessa forma, entende-se que as etapas referentes à elaboração de um fanzine, tais como a pesquisa, a contextualização da temática escolhida ao perfil dos estudantes, e os questionamentos surgidos durante o processo podem vir a propiciar situações de ensino e aprendizagem, bem como reflexões relevantes no que tange à utilização de linguagens e recursos didáticos diversos no Ensino de Ciências.

\section{CONSIDERAÇÕES FINAIS}

O trabalho com fanzines possibilita o uso de diferentes linguagens, bem como pode ser utilizado como instrumento de divulgação científica. A atividade de pesquisa associada à produção de um fanzine abre espaço para a descoberta de novos conhecimentos e aprofundamento ou reorganização de conceitos já internalizados pelos estudantes.

Dessa forma, a elaboração de fanzines pode ser utilizado como um recurso didático na formação dos pedagogos que irão ensinar temas científicos na educação básica, pois ao realizarem o exercício de tornar a linguagem científica acessível e compreensível para seus estudantes por meio do fanzines, eles podem perceber a importância de abordar temas científicos por meio da aproximação de aspectos do cotidiano dos estudantes.

Outro ponto positivo da elaboração de fanzines é o exercício de uma escrita criativa e crítica, pois ao exercer a autoria de um fanzine, os professores em formação podem discutir temas de uma forma mais livre e autônoma, já que esse tipo de publicação não apresenta uma estrutura única.

Recebido em: 23/04/2021

Aceite em: 20/09/2021 
Assim, entende-se que o trabalho com fanzines agrega aprendizagens e posturas que beneficiam a formação inicial do pedagogo e sua atuação no Ensino de Ciências. A atividade de pesquisa, a busca por uma temática socialmente relevante, bem como a elaboração de um recurso para divulgação científica caracterizam-se como elementos que contribuem para a formação do pedagogo, especialmente no que tange às metodologias para o Ensino de Ciências.

\section{REFERÊNCIAS}

ANDRAUS, G. Minhas experiências no ensino com os criativos fanzines de histórias em quadrinhos e outros temas. p. 82-93. In: SANTOS NETO, Elydio dos; SILVA, Marta Regina Paulo da. (Orgs.). Histórias em quadrinhos e práticas educativas: o trabalho com universos ficcionais e fanzines. São Paulo: Editora Criativo, 2013.

BERALDO, T.M.L.; CEZARI, E.J. Pedagogia, pedagogos e a formação para o ensino de ciências naturais na educação infantil e nos anos iniciais do ensino fundamental: uma análise no contexto das atuais políticas curriculares nacionais. In: ENCONTRO NACIONAL DE DIDÁTICA E PRÁTICAS DE ENSINO, 16, 2012, Campinas. Anais eletrônicos...Campinas: UNICAMP, 2012. p. 14-25. Disponível em:

http://www.infoteca.inf.br/endipe/smarty/templates/arquivos_template/upload_arquivos/acerv o/docs/2158c.pdf . Acesso em 23 jan. 2017.

BEZERRA, D. B.; SANTOS, A. C. Ensino de Ciências na educação de jovens e adultos: (res)significando saberes na produção de fanzines. Revista de Educação, Ciências e Matemática, v.6, n1, p 93-106, jan/abr 2016. Disponível em: http://publicacoes.unigranrio.edu.br/index.php/recm/article/view/3339/1771. Acesso em: 08 ago. 2021.

BEZERRA, J. C. O.; OLIVEIRA, T. E. S.; ALMEIDA, L. B. Fanzine como ferramenta pedagógica educomunicativa. In: CONGRESSO DE CIÊNCIAS DA COMUNICAÇÃO NA REGIÃO NORDESTE, 19, 2017, Fortaleza. Anais eletrônicos... São Paulo: Intercom, 2017, p. 1-10 Disponível em: https://portalintercom.org.br/anais/nordeste2017/resumos/R57-03061.pdf. Acesso em 28 jun. 2021.

BRASIL. Base Nacional Comum Curricular: Educação Infantil e Ensino Fundamental. Brasília: MEC/Secretaria de Educação Básica, 2017.

BIZZO, N. Ciências: fácil ou difícil? São Paulo: Biruta, 2009.

CACHAPUZ, A.; GIL-PEREZ, D.; CARVALHO, A.M.P.; PRAIA, J.; VILCHES, A. (Orgs.) A necessária renovação do ensino das ciências. 3. ed. São Paulo: Cortez, 2011. 264p.

COUTINHO, C.; MIRANDA, A. C. Formação inicial de professores de Ciências da Natureza: relatos de uma prática docente diferenciada. Revista Insignare Scientia - RIS,

Recebido em: 23/04/2021

Aceite em: 20/09/2021 
Chapecó, v. 2, n. 2, p. 221-231, 19 set. 2019. Disponível em: https://periodicos.uffs.edu.br/index.php/RIS/article/view/10876/7219. Acesso em: 01 jun. 2021.

LEITE, R.C.M.; MIRANDA, R. S.; MOTA, M.D.A. Formação de professores de Ciências para os anos iniciais: relato de uma vivência com a produção de fanzines no curso de Pedagogia. In: SILVA, Wanderson Diogo Andrade da; FREITAS, Bruno Miranda; COSTA, Elisangela André da Silva (Orgs.). Experiências da formação de professores na escola e na universidade. Porto Alegre, RS: Editora Fi, 2020.

LIMA, T.R.; MIRANDA, L.L. Subjetividades de papel. p. 48-65. In: MUNIZ, C.R. (Org.). Fanzines: autoria, subjetividade e invenção de si. Editora UFC, 2010. 139 p.

LORENZETTI, L.; DELIZOICOV, D. Alfabetização Científica no contexto das séries iniciais. Revista Ensaio, Belo Horizonte, v. 03, n. 01, p. 45-61, jan/jun, 2001. Disponível em: https://www.scielo.br/pdf/epec/v3n1/1983-2117-epec-3-01-00045. Acesso em: 01 jun. 2021.

MAGALHÃES, H. Fanzines de histórias em quadrinhos: conceito e contribuições a educação. p. 52- 67. In: SANTOS NETO, E.; SILVA, M.R.P. (Orgs.). Histórias em quadrinhos e práticas educativas: o trabalho com universos ficcionais e fanzines. São Paulo: Editora Criativo, 2013. 112 p.

MIOLA, P.; PIEROZAN, S.S.H. O ensino de ciências na formação do pedagogo. In: EDUCERE- CONGRESSO NACIONAL DE EDUCAÇÃO, 12, 2015, Curitiba. Anais eletrônicos... Curitiba: Pontifícia Universidade Católica do Paraná, 2015, p.20928-20941. Disponível em: http://educere.bruc.com.br/arquivo/pdf2015/21237_10564.pdf. Acesso em 23 abr. 2017.

MUNIZ, C.R. Na desordem da palavra: fanzines e a escrita de si. p. 15- 28 In: MUNIZ, C.R. (Org.). Fanzines: autoria, subjetividade e invenção de si. Editora UFC, 2010. 139 p.

NASCIMENTO, I.S. Da marginalidade à sala de aula: o fanzine como artefato cultural, educativo e pedagógico. p. 121- 133. In: MUNIZ, C.R. (Org.). Fanzines: autoria, subjetividade e invenção de si. Editora UFC, 2010. 139 p.

OESTREICH, L.; PAIM, M. G.; BREUNIG, E. T.; GOLDSCHMIDT, A. I. O que é ciência? Uma análise das concepções prévias de docentes em formação inicial. Revista Insignare Scientia - RIS, Chapecó,v. 4, n. 3, p.160-178. Edição Especial: I SSAPEC - Simpósio SulAmericano de Pesquisa em Ensino de Ciências, 2021. Disponível em: https://periodicos.uffs.edu.br/index.php/RIS/article/view/12119. Acesso em: 01 jun. 2021.

POZO, J. I. CRESPO, M. Á. G. A aprendizagem e o ensino de ciências: do conhecimento cotidiano ao conhecimento científico. Tradução Naila Freitas. 5. ed. Porto Alegre: Artmed, 2009.

SANTOS NETO, E. Dos zines aos biograficzines: compartilhar narrativas de vida e formação com imagens, criatividade e a autoria. p. 29-47. In: MUNIZ, C.R. (Org.). Fanzines: autoria, subjetividade e invenção de si. Editora UFC, 2010.

Recebido em: 23/04/2021

Aceite em: 20/09/2021 